\title{
DOSSIÊ
}

\section{Violencia homicida y estructuras criminales en Bogotá}

MARÍA VICTORIA LLORENTE, RODOLFO ESCOBEDO, CAMILO ECHANDÍA E MAURICIO RUBIO

\section{Introducción: contexto y dimensión del problema de la violencia en Bogotá}

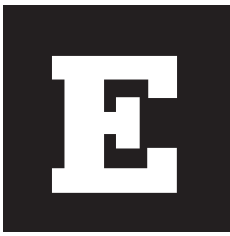

n Bogotá habita el 15\% de la población del país, cerca de seis y medio millones de personas. Cali y Medellín, ciudades que le siguen en número de habitantes, en su conjunto concentran el $10 \%$ de la población nacional con una cifra que ronda los dos millones de habitantes respec-

tivamente.

Como es previsible, dada la gran cantidad de población que alberga, Bogotá es uno de los centros urbanos que más aporta al número de homicidios en Colombia. Así, durante la última década ha concentrado el $11 \%$ del total de homicidios en el país ${ }^{1}$. Sin embargo, no se distingue por ser una de las ciudades más violentas del país. De hecho, desde mediados

\footnotetext{
*Investigadores del Programa de Estudios Paz Publica - Centro de Estudios sobre Desarrollo (CEDE)- Universidad de Los Andes, Bogotá-Colombia. E-mail: pazpubl@uniandes.edu.co.

María Victoria Llorente. Politóloga de la Universidad de los Andes de Bogotá. Coordinadora del Programa Paz Pública del Centro de Estudios para el Desarrollo Económico, CEDE, de la Universidad de los Andes desde su creación en 1997.

Rodolfo Escobedo. Politólogo de la Universidad de los Andes de Bogotá con un DEA en Sociología de l'Ecole D'Hautes Etudes en Sciences Sociales de Paris.

Camilo Echandía. Economista de la Universidad Externado de Colombia. Actualmente es profesor titular de la Universidad Externado, profesor de la Universidad de Los Andes, investigador asociado del Programa Paz Pública de la misma universidad y consultor del Observatorio de Violencia y Derechos Humanos de la Vicepresidencia de la República.

Mauricio Rubio. Economista de la Universidad de los Andes y candidato a PhD en economía de la Universidad de Harvard. Actualmente es profesor de la Universidad Carlos III en Madrid, consultor internacional del Banco Interamericano de Desarrollo en programas sobre justicia y seguridad en Centro América e investigador asociado del Programa Paz Pública del Centro de Estudios para el Desarrollo Económico, CEDE, de la Universidad de los Andes.

1 Esta cifra sólo la sobrepasa Medellín, donde en la última década se presentaron el $16 \%$ del total de homicidios del país. Cali por su parte aportó el 7\% del total de homicidios de la Nación. En su conjunto, las tres grandes ciudades (Bogotá, Cali y Medellín) han concentrado alrededor de una tercera parte de los homicidios del país ocurridos en la década de los noventa.
} 
de los noventa Bogotá ha presentado una tasa de homicidios ${ }^{2}$ relativamente baja al nivel nacional y, actualmente, es bastante inferior a la de la mayoría de las capitales de Departamento del país ${ }^{3}$.

La tasa de homicidios en Bogotá ha descendido permanentemente desde 1994. En el 2000 se observó un nivel de homicidios, cercano al de doce años atrás, antes de iniciarse un período de ascenso en 1988 que se prolongó hasta 1993. En este año la tasa de homicidios de Bogotá sobrepasó a la nacional, llegando a 80 homicidios por cien mil habitantes (hpcmh). Desde 1994 la tendencia creciente se revirtió y se pasó de 66 hpcmh en ese año, a $35 \mathrm{hpcmh}$ en el 2000. Esta última tasa es la mitad de la nacional para el 2000, y es casi cinco veces menor a la de Medellín, ciudad que en la última década ha exhibido uno de los más altos índices de violencia dentro del contexto urbano colombiano (Gráficas 1 y 2).

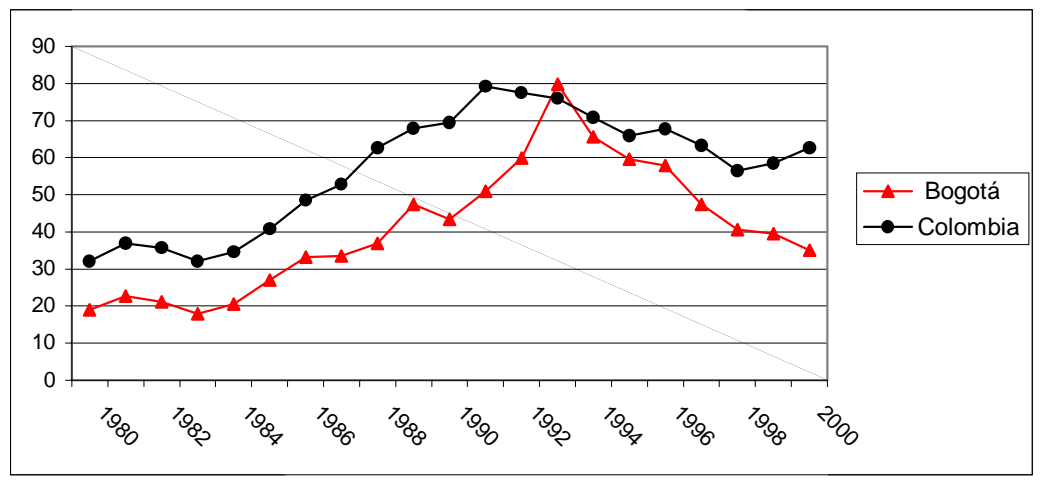

Fuente: Policía Nacional e Instituto Nacional de Medicina Legal

Grafica 1. Tasa de homicidios Colombia y Bogota - 1980-2000

2 Definida como el número anual de homicidios por cada cien mil habitantes.

3 Dentro de las 33 ciudades capitales de Departamento en Colombia, la tasa de homicidios de Bogotá ocupó el lugar número 23 en el 2000, la de Medellín y Cali tuvieron el segundo y octavo puesto respectivamente. Seis años atrás, la tasa de homicidios de Bogotá ocupaba el puesto número 12 y la de Medellín y Cali el primer y segundo lugar respectivamente. 


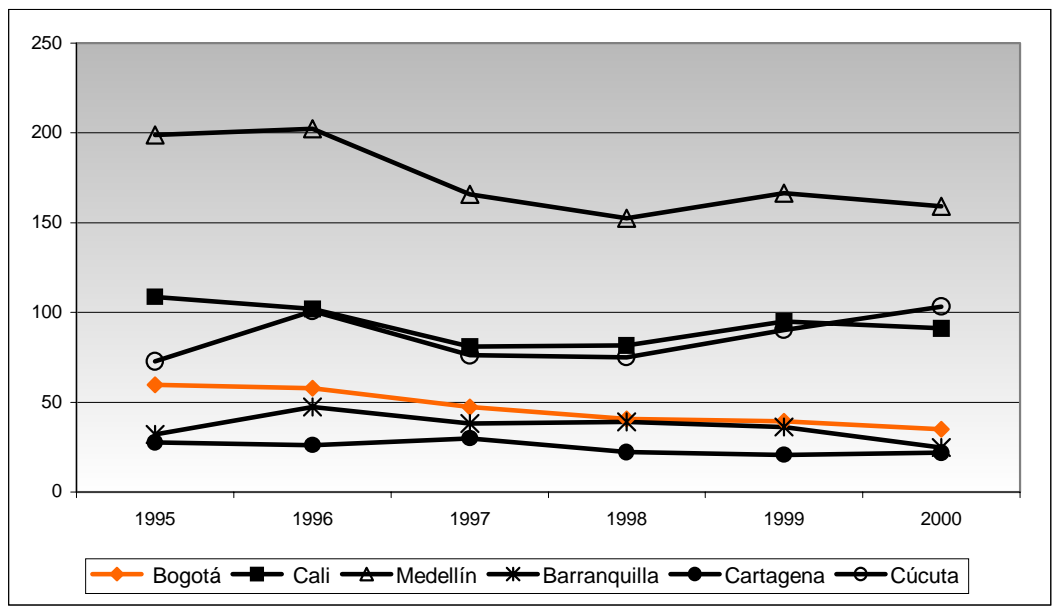

Fuente: Policía Nacional e Instituto Nacional de Medicina Legal

Gráfica 2. Tasa de homicidios principales centros urbanos de Colombia 1995-2000

Si bien actualmente Bogotá no es tan violenta al nivel nacional, la dimensión del problema sigue siendo considerable bajo cualquier estándar internacional. En Latino América, donde en la última década se ha incrementado la preocupación por los fenómenos de violencia, dado que es calificada internacionalmente como una de las regiones con los más altos índices de homicidio, a finales de los noventa se observaba una tasa promedio de $30 \mathrm{hpcmh}$ - es decir, cinco puntos por debajo de la registrada en Bogotá en el 2000.

Pero más allá de estas comparaciones, el aspecto que quizás resulta más relevante es que claramente en ciertas zonas de la ciudad las tasas de homicidio son críticas. En efecto, los datos desagregados de homicidio entre 1997 y 1999 muestran que un porcentaje no despreciable, 16\%, de los sectores censales de Bogotá presenta tasas superiores a 100 homicidios por cien mil habitantes, nivel normalmente asociado con situaciones de guerra. Dentro de esta dimensión se destacan prácticamente todos los sectores de las localidades del centro de la ciudad y algunas zonas de localidades peri- 
féricas del sur caracterizadas por altos indicadores de violencia.

Muy poco se sabe hasta el presente acerca de los cambios bruscos en la tendencia de homicidios en Bogotá observados desde finales de los ochenta. Menos aún sobre lo que ocurre en aquellas zonas de la ciudad intensamente violentas. Mientras que no hay explicaciones satisfactorias para la dinámica registrada en Bogotá, para Medellín y Cali, donde en los últimos veinte años se asentaron poderosos carteles de la droga, está relativamente documentada la estrecha asociación entre los índices de violencia y las actividades de estas organizaciones criminales ${ }^{4}$.

Mapa 1. Tasa de homicidios Bogota según localidades - Promedio 1997-1999

\footnotetext{
1. Usaquen

2. Chapine ro

3. Santa Fé

4. San Cristo bal

5. Usme

6. Tunjuelito

7. Bosa

8. Kenedy

9. Fontibón

10. Engativa

11. Suba

12. Bamios Unid os

13. Te usaquillo

14. Martires

15. Antonio Nariño

16. Puente Aranda

17. Candelaria

18. Rafael Uribe

19. Ciudad Bolívar
}

Taso $97-99$

$[129,255.04]$

$\square[86,129$ [

$20.17,21$

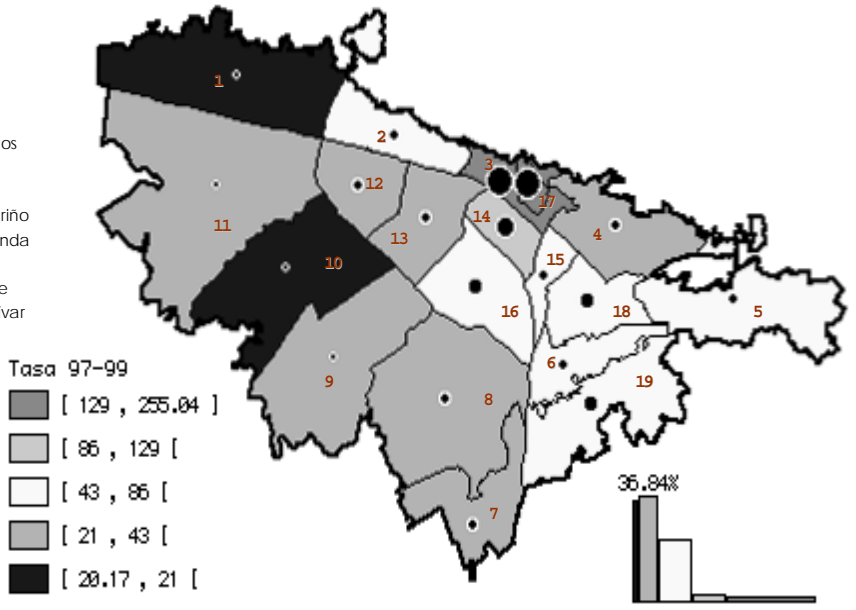

Tasa $97-99$

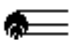

霄

Cabral 1500 Versión 2.3

Fondo de Mapa CEDE-ORSTOM (O. Pissoat)

4 Resulta particularmente interesante el estudio de Sánchez y Núñez (2000), que mediante una innovadora metodología para medir la magnitud del narcotráfico en varias ciudades del país, deduce que en el caso de Medellín por ejemplo, cerca de un $80 \%$ del incremento en la tasa de homicidios en los años ochenta puede ser atribuido al incremento de la actividad del narcotráfico. Este tipo de asociación, por lo demás, está ampliamente documentada en literatura internacional. 
Lo cierto es que el caso de Bogotá no ha sido suficientemente estudiado $^{5}$ y prevalecen una serie de mitos en torno a las causas de la violencia en la ciudad que no han sido adecuadamente sustentados. Así, dentro de los diagnósticos convencionales se ha ignorado la posible incidencia de formas de crimen organizado en los niveles de violencia, en la medida en que la capital no ha estado cruzada por los fenómenos del narcotráfico y del conflicto interno como lo han estado otros grandes centros urbanos del país.

Este artículo tiene por objeto realizar, precisamente, una aproximación a la incidencia de estructuras criminales en los niveles de homicidio en Bogotá, a partir de un análisis de las distintas manifestaciones de la violencia y algunos de sus factores determinantes, así como del patrón espacial y de difusión de los homicidios en la ciudad. En esta medida, no se hará una caracterización de las estructuras que operan en la capital, sino más bien se pretende poner de relieve el hecho que en Bogotá, contrariamente a lo que comúnmente se ha creído en el país, la intensidad de la violencia en las zonas más conflictivas está asociada a la presencia y actividad de formas organizadas del crimen.

Vale anotar que utilizamos el término de estructuras criminales para identificar a la importante gama de bandas y grupos que se dedican a numerosas actividades ilícitas y del "bajo mundo" 6 en Bogotá. Dentro del mismo caben también, algunas agrupaciones de autodefensa que han surgido en ciertas zonas de la ciudad para enfrentar la delincuencia y milicias urbanas de la guerrilla. Estas estructuras aunque varían considerablemente

\footnotetext{
5 Entre los pocos estudios sobre Bogotá se destacan los de Duque y Klevens (1997 y 2000) que aplicando el enfoque epidemiológico, pretenden establecer los factores individuales y familiares asociados a los comportamientos violentos de los bogotanos, así como el de Jimeno y Roldán (1996) que, desde la visión antropológica y psicológica, explora las percepciones que los pobladores de sectores populares de Bogotá tienen sobre la violencia en el hogar y por fuera de él. También se encuentran aproximaciones al fenómeno del sentimiento de inseguridad de los bogotanos, que buscan identificar las zonas que mayor temor generan y los factores que según los ciudadanos hacen que esos sitios sean particularmente temidos (Niño et alii, 1998). 6 Entre estas actividades se destacan: atraco callejero, asalto bancario, robo y halado de vehículos, hurto a residencias y a establecimientos comerciales, asaltos a vehículos repartidores, prostitución, compra-ventas, reducidores, extorsión y secuestro, venta de drogas ilícitas, tráfico de armas de fuego y sicariato. Para una caracterización de estas estructuras al nivel local y barrial ver Paz Pública (2000 y 2000a).
} 
en cuanto a organización y a tipo de actividad a la que se dedican, tienen un común denominador: el uso de la violencia expresado en ajustes de cuentas entre ellas y al interior de ellas, en intimidación a la población, en "limpiezas sociales"7 y en ataques tanto contra los organismos de seguridad del Estado, como contra los ciudadanos con fines de lucro. Este término sirve igualmente para marcar una diferencia con el de crimen organizado que usualmente se utiliza en Colombia para caracterizar las grandes mafias del narcotráfico y, más recientemente, los comportamientos de los grupos guerrilleros y paramilitares en algunas zonas del país.

Para realizar el estudio del cual se desprende este escrito, se utilizaron varios métodos y fuentes. Por una parte, se hizo un análisis estadístico y espacial ${ }^{8}$ de los homicidios y de los posibles móviles que los ocasionaron en el período 1997-1999, a partir de la base de datos configurada por el Centro de Referencia Nacional sobre Violencia del Instituto Nacional de Medicina Legal y Ciencias Forenses. De manera complementaria se utilizaron también, las bases de datos disponibles en la Alcaldía con indicadores demográficos, sociales y de presencia del Estado.

Por otra parte, se efectuó un trabajo de identificación de estructuras criminales por barrios de la ciudad, nunca hecho hasta el momento, basado en entrevistas a policías que trabajan en las distintas estaciones de las 19 localidades urbanas de Bogotá9. Dentro de este trabajo se identificaron adicionalmente las zonas donde, según la percepción de la policía, se concentran diversas actividades ilícitas sobre las cuales no existen estadísticas precisas - atracos callejeros, venta y consumo de drogas ilícitas, tráfico de armas- y sitios considerados especialmente conflictivos porque sirven de

7 Hace alusión al fenómeno de eliminación sistemática de delincuentes, habitantes de la calle, drogadictos y prostitutas, entre otros.

8 Los análisis espaciales se hicieron en dos niveles de desagregación geográfica. Primero, la localidad que corresponde a la división político-administrativa de la ciudad. Bogotá cuenta con 19 localidades urbanas y una rural (Sumapáz) que no se incluyó dentro del análisis. El segundo nivel, el sector censal, es la unidad espacial utilizada para hacer censos de población. Bogotá está dividida en 603 sectores censales. Al nivel más desagregado se encuentran los barrios (existen alrededor de 1500 en Bogotá), pero esta unidad no fue estudiada debido a que la ciudad no cuenta con un mapa confiable de barrios.

9 Complementariamente se entrevistaron miembros de otros organismos como el Departamento Administrativo de Seguridad, DAS, el Cuerpo Técnico de Investigaciones, CTI, la Dirección de Inteligencia de la Policía y el Ejército. Para la metodología del trabajo de campo y la construcción de la correspondiente base de datos ver Paz Pública (2000). 
escenario para la ocurrencia de escándalos y riñas que en ocasiones resultan en lesiones no fatales y fatales - bares, tabernas, prostíbulos, moteles, billares, sitios de apuestas. Esto permitió configurar un primer mapa ${ }^{10}$ de presencia territorial de estructuras criminales que fue analizado a la luz tanto del patrón espacial de los homicidios en la capital, como de la identificación preliminar de zonas donde se concentran mercados ilegales y sitios conflictivos.

Este artículo está dividido en cinco partes. En la primera se debaten las creencias más comunes sobre la violencia urbana en Colombia; en la segunda se analizan las distintas manifestaciones de la violencia en Bogotá; en la tercera se presenta la evidencia sobre el patrón geográfico de los homicidios en la ciudad; en la cuarta se aborda la asociación entre factores sociales y violencia y, en la quinta, se aproxima la relación entre violencia y estructuras criminales en la ciudad. Al final se presentan las principales conclusiones del diagnóstico encontrado y sus implicaciones sobre la política pública.

\section{Mitos sobre la violencia urbana en Colombia}

En el debate público colombiano han hecho carrera varios mitos sobre la violencia urbana, los cuales en buena medida se desprenden de teorías sustentadas en evidencia propia de contextos de violencia bien distintos, en particular, aquellos donde las tasas de homicidios escasamente sobrepasan los dos dígitos. Sin embargo, son verdaderamente pocos los estudios locales que corroboran empíricamente tales mitos.

Un primero mito es que el mayor número de muertos en los contextos urbanos del país lo produce una violencia cotidiana producto de la intolerancia entre ciudadanos. Dentro de este tipo de violencia, que denominamos impulsiva, las expresiones más comunes son, por un lado, el maltrato en el hogar y por el otro, los ataques por fuera de éste como las

10 Por razones de espacio no fue posible reproducir los mapas a que se hace referencia en este artículo. 
riñas, disputas o altercados que, en el bar o en la calle, se salen de las manos y terminan fatalmente. En contraposición está la violencia de tipo instrumental, aquella que se usa con algún fin y que se asocia en especial con formas relativamente organizadas del crimen y con grupos armados irregulares ${ }^{11}$.

Sorprende que en Colombia, país mundialmente reputado por el poder de sus organizaciones criminales y la intensidad del conflicto armado, se siga postulando que "la violencia cotidiana en las ciudades ... es la causa de la mayoría de los homicidios y lesiones no fatales del país" (Duque y Klevens, 2000, p. 188). Más sorprendente aún es que, la evidencia testimonial o estadística - que se ha ofrecido en el país acerca del predominio de la violencia impulsiva es en extremo débil, cuando no inexistente. Por una parte, según datos de Medicinal Legal, las riñas no son la principal causal de los homicidios en las urbes colombianas, salvo en contextos de baja intensidad de la violencia, en las zonas más violentas claramente predominan el misterio sobre los móviles de los homicidios, los ajustes de cuentas y los atracos (Paz Pública, 1997). Por otra parte, el maltrato en el hogar no solo es una de las manifestaciones que aporta el menor número de muertes, sino que además Colombia, exhibe unos índices de violencia en el hogar que no son excepcionalmente altos en el contexto latinoamericano ${ }^{12}$.

Resulta interesante anotar que en distintos lugares y para distintas épocas este tipo de mito ha sido relativamente común. En Estados Unidos

11 La distinción entre estos dos tipos de violencia, impulsiva e instrumental, resulta especialmente pertinente dentro del contexto del debate público colombiano. Parte del problema de la definición del diagnóstico y de las políticas de prevención del crimen para el caso colombiano, se origina precisamente en la tendencia a equiparar modalidades de homicidio disímiles en términos de naturaleza y actores involucrados, bajo un concepto genérico de violencia. Así, por ejemplo, se considera que un homicidio ocasionado al calor de unos tragos en una taberna es equivalente al ocurrido en el curso de un atraco o de un ajuste de cuentas entre bandas. Esta distorsión se traduce en políticas que pretenden confrontar situaciones verdaderamente distintas en términos de su naturaleza y del tipo de actores que involucra. Para un análisis sobre las imprecisiones presentes en el debate nacional sobre la violencia ver Rubio (1999). Para hacer esta distinción tomamos la tipología sobre violencia impulsiva e instrumental de Spierenburg (1996), desarrollada a partir del análisis de la evolución del crimen en Holanda desde la Edad Media hasta el siglo veinte.

12 Según Buvinic y Morrison (1999) los índices de violencia doméstica colombianos son bastante similares a los de Chile y Costa Rica e inferiores a los de Perú, Nicaragua o México. 
en los cincuenta y sesenta, así como varios siglos atrás en Inglaterra, distintos estudios basados en el análisis de expedientes judiciales han resaltado la preponderancia de la violencia impulsiva, en especial de la resultante de riñas ${ }^{13}$. Sin embargo estos estudios, no sólo no hacen alusión a los niveles de violencia ni a que esas comunidades analizadas estuvieran sujetas a la influencia de organizaciones armadas ilegales, sino que además, asumen que los incidentes que aclara la justicia son un reflejo de lo que ocurre en la realidad. Como se ha demostrado para el caso colombiano este último no siempre es así, y lo que se aprecia es un marcado sesgo judicial por resolver los homicidios impulsivos en detrimento de aquellos instrumentales (Rubio, 1998 y 1999) $)^{14}$.

Un segundo mito, como extensión del primero, es que de la violencia impulsiva se escala hacia expresiones más organizadas de la instrumental. Se parte del supuesto de que hay una causalidad de la violencia que se inicia en las manifestaciones menos graves, como la agresión en el hogar, y se va escalando progresivamente hacia las situaciones más serias, incluso las mafias o el paramilitarismo. Así, se plantea que la generalización de la violencia impulsiva facilita que surjan actividades criminales o conflictos sociales de gran envergadura; la violencia en el hogar induce la violencia impulsiva en la calle que, a su vez, conduce a manifestaciones cada vez más graves de violencia criminal ${ }^{15}$.

Fuera de los Estados Unidos, los trabajos empíricos que permitan corroborar este tipo de asociación aún son insuficientes ${ }^{16}$. En uno de los pocos estudios disponibles para otras sociedades, luego de comparar noventa culturas diferentes alrededor del mundo, se sugiere que, en efecto,

\footnotetext{
13 Sobre estos ejemplos ver Daly y Wilson (1988) y Lane (1979).

14 Para el caso de Bogotá ver Rubio y Llorente (2000). Vale la pena señalar además, que el porcentaje de homicidios que se juzgan en Colombia es sólo una pequeña fracción de los que realmente ocurren.

15 Este enfoque ha empezado a plantearse con fuerza para el conjunto de América Latina en trabajos que pretenden orientar las políticas de prevención del crimen en la región como los de Guerrero (1997), Arriagada y Godoy (1999), Buvinic y Morrison (1999), Buvinic et alii(1999), Londoño y Guerrero (1999).

16 Para Colombia se han hecho unas pocas aproximaciones preliminares en Duque y Klevens (1997), Klevens y Roca (1999) y Klevens et aliii(1999).
} 
en las sociedades pacificadas, en donde los hombres son poco violentos en la calle, es menos probable la violencia en el hogar ${ }^{17}$.

Un último mito es que existen unas "causas objetivas" que explican la violencia en el país. Se postula aquí que, en particular, la violencia instrumental, ejercida tanto por los delincuentes comunes como por actores más organizados, está determinada por factores sociales y económicos tales como la pobreza, la desigualdad o injusticia social, el desempleo y la marginalidad producto de los excesivos flujos migratorios del campo hacia la ciudad ${ }^{18}$. Todavía en este caso, donde de alguna manera se reconoce la pertinencia de la violencia instrumental, se considera que en sus orígenes hubo una inducción a la violencia como consecuencia de las condiciones sociales. Así, el análisis se concentra en las condiciones iniciales bajo las cuales el individuo marginado aprendió los comportamientos violentos y, consecuentemente, emprendió una carrera criminal o se vinculó a un grupo insurgente.

Esta tesis, sin duda, es la más aceptada y la que mayor impacto ha tenido sobre la política pública del país de la última década y a la vez, la que cuenta con evidencia empírica más difícil de interpretar y menos contundente. Al nivel internacional, Fajnzylber et alii (1999), al comparar un número importante de países ha demostrado que si bien no hay una asociación entre niveles de pobreza y crimen, sí se observa una relación de causalidad entre desigualdad y violencia. En Colombia, trabajos pioneros de Echandía (1992 y 1995) y Gaitán (1995) indicaron que, contrariamente a lo esperado, la evidencia municipal mostraba que los altos índices de violencia se concentraban en aquellas zonas más ricas del país, desvirtuando así la tesis que vincula la pobreza con la violencia.

Más recientemente, se han realizado aproximaciones con evidencia municipal y departamental que sustentan la relación entre violencia y

17 Ver Levinson, D. (1989) Family Violence in Cross-Cultural Perspective. Newbury Park, C.A.: Sage citado por Klevens (1998). 18 En Colombia el trabajo que desarrolló inicialmente esta tesis y que mayor influencia ha tenido sobre el debate público ha sido el de la Comisión de Estudios sobre la Violencia (1987). 
desigualdad en Colombia, pero en los cálculos no se incluyeron factores centrales como el narcotráfico y el conflicto interno (Sarmiento, 1999). Otros estudios, que sí consideran estas variables, también a partir de datos locales y regionales, han corroborado que ni la pobreza, ni la desigualdad, producen en Colombia una violencia diferente de la que puede generar en otros países (Rubio, 1997 y 1999; Echandía, 1997 y 1999; Gaviria, 1999; Sánchez y Núñez, 2000). Concluyen estos trabajos entonces, que la tasa de homicidios desmesurada que distingue al país, se explica primordialmente por la presencia y actividad de grupos armados irregulares - narcotráfico, guerrilla y paramilitares - y el deficiente desempeño de la justicia.

En síntesis, el común denominador de estos mitos es que por un lado, se percibe la violencia como un fenómeno generalizado, fruto de una cultura que hace a los colombianos particularmente intolerantes y por el otro, se ignora, minimiza, o explícitamente niega, la incidencia de la violencia organizada y sus posibles vínculos con la delincuencia común. Para el caso de Bogotá, quizás por las tasas de homicidio relativamente bajas que ha exhibido desde mediados de los noventa, se ha tendido a aceptar, sin mayor discusión, el diagnóstico que se desprende de estas creencias comunes. Sin embargo, como se verá en los siguientes apartes de este artículo, estos mitos tampoco parecen pertinentes para caracterizar la violencia en la capital de Colombia.

\section{Violencia impulsiva e instrumental en Bogotá}

El análisis de los móviles de los homicidios en Bogotá durante el período 1997-99 contrasta de manera importante con el supuesto de la preponderancia de la violencia impulsiva. A todas luces, para el caso de Bogotá, los datos indican que para las muertes violentas sobre las cuales se dispone de alguna información en cuanto a los móviles ${ }^{19}$, lo que predomina 
es la dimensión instrumental, en particular los ajustes de cuentas y los atracos. El número de homicidios instrumentales es, en promedio para la ciudad, 2.5 veces superior al de casos que se pueden considerar impulsivos; en ninguna de las localidades es más pertinente la incidencia de los segundos (en todos los casos la relación es superior a 1.8) y en algunas localidades, alcanza a haber 4.4 homicidios instrumentales por cada caso impulsivo.

Otro elemento que se destaca es que los dos tipos de violencia están positiva y estrechamente asociados: la correlación entre uno y otro indicador, por localidades, es del 94\%. Las localidades en donde se presenta una alta incidencia de homicidios instrumentales son precisamente aquellas donde se registra un mayor número de casos impulsivos - especialmente muertes por riña. Esta asociación, por lo demás, se torna más estrecha a medida que aumentan los niveles de violencia. En efecto, si se excluyen de la muestra las tres localidades para las cuales ambos tipos de violencia son superiores al promedio de la ciudad, la correlación entre los indicadores de uno y otro tipo de violencia se reduce considerablemente (al 62\%).

Esta asociación podría interpretarse como que una de las violencias "jalona" a la otra, en particular cuando se presentan niveles altos de homicidio, por encima de $60 \mathrm{hpcmh}$. E incluso se podría asimilar al supuesto de causalidad de la violencia según el cual de la tipología impulsiva se va escalando hacia la instrumental. Sin embargo, esto no parece ser lo que revelan los datos. Lo que sale a la luz es que a partir de ciertos niveles de violencia, la alusión a los móviles, como las discusiones o las riñas, puede guardar menos relación con lo que realmente ocurre en los incidentes y que más bien, tras de estos casos se esconden manifestaciones de la violencia instrumental.

El establecimiento de los posibles móviles por parte de las autoridades está directamente asociado con la escala de violencia, así como lo están las expresiones de los dos tipos de violencia. Por un lado, el análisis 
de los móviles al nivel de sector censal indica que a mayor intensidad de la violencia, mayor es el desconocimiento sobre las posibles causas de los homicidios (Gráfica 3). Por otro lado, se observa que en la medida en que se intensifica la violencia, la calificación del móvil tiende progresivamente hacia las causas instrumentales y que por el contrario, los casos de violencia impulsiva parecerían ser relevantes únicamente cuando la intensidad de la violencia es baja (Gráfica 4).

Fuente: Cálc HOMICIDIOS SIN INFORMACIóN MOVIL

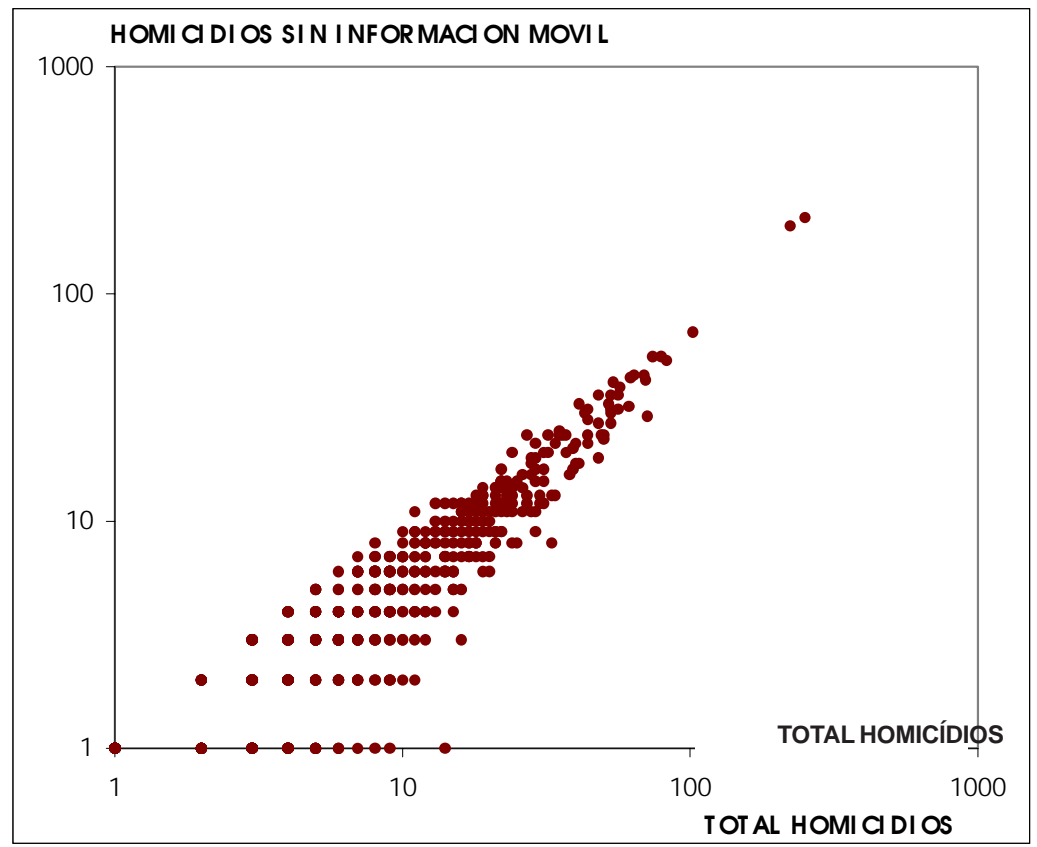

Grafica 3.La desinformación aumenta con la violencia Total de homicidios y casos sin información por sectores censales 1997-1999 - Escala Logaritmica 

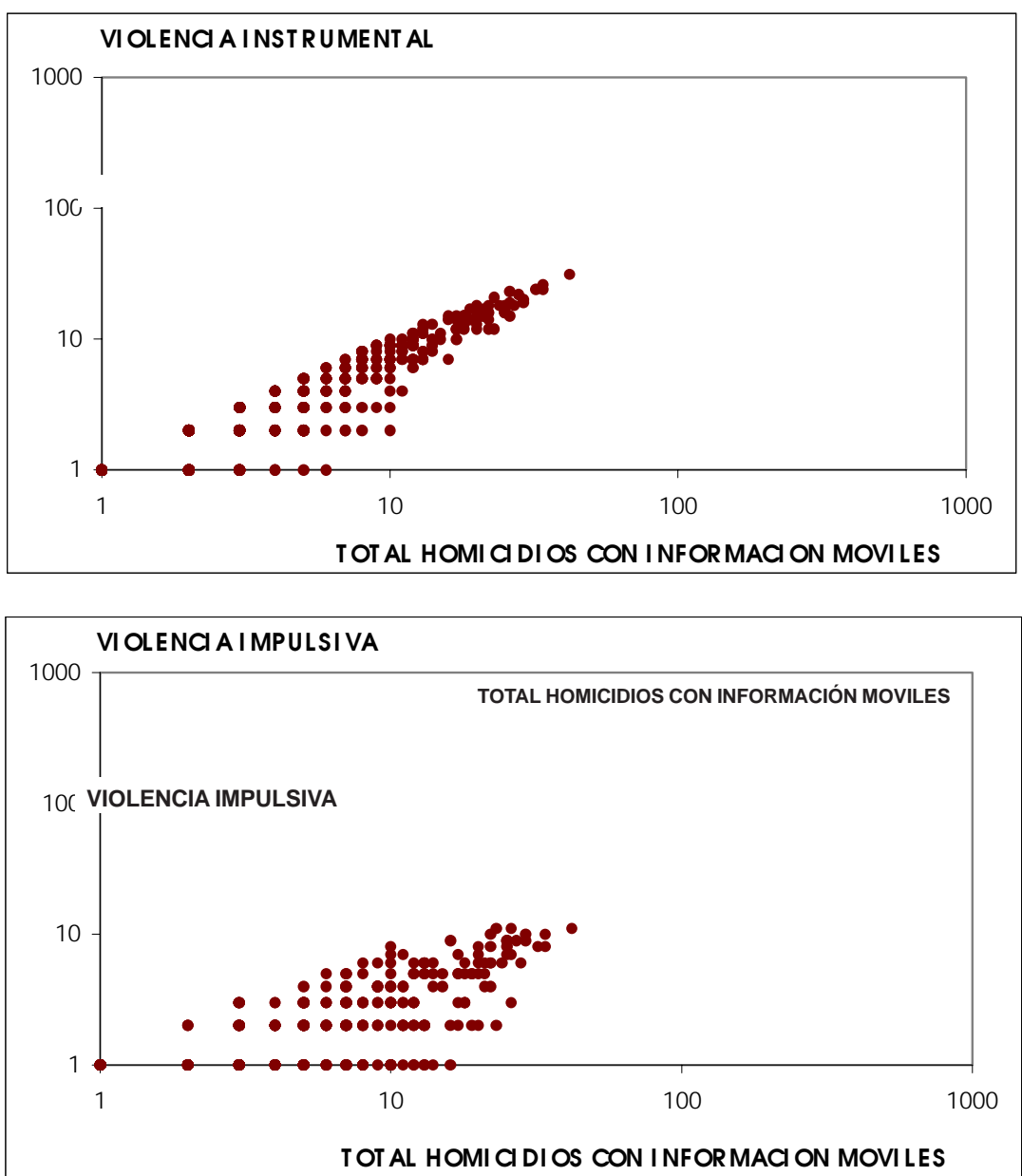

VIOLENCIA INSTRUMENTAL

TOTAL HOMICIDIOS CON INFORMACIÓN MOVILES

Fuente: Cálculos propios con datos Homicidios Medicina Legal - Sectores Infographics

Grafica 4. La información sobre moviles tiende a lo instrumental Homicidios con Información y en cada categoría - Por sectores censales 1997-1999 - Escala Logaritmica 
Otro elemento que debe tomarse en cuenta es la precariedad de la definición de la categoría de riñas y por ende, de la información que bajo ese rótulo se registra por parte de las autoridades. Parecería que, bajo esta categoría, tienden a agruparse aquellos incidentes para los cuales no se sabe muy bien lo que ocurrió ${ }^{20}$.

Un indicador interesante de las deficiencias en la información de muertes, que supuestamente resultan de riñas, es la falta de consistencia entre la geografía de los homicidios por este móvil y la distribución de los reportes de la Policía Metropolitana de Bogotá sobre denuncias por riñas. En efecto, para 1999 las localidades con un alto número de denuncias por riñas no se destacaron por un alto número de muertes violentas por tal causal. El trabajo de campo efectuado en las distintas localidades de Bogotá es rico en ejemplos indicativos de que, tras de supuestas muertes por riña, se esconden ajustes de cuentas entre estructuras criminales (Paz Pública, 2000 y 2000a).

En fin, es posible concluir que, bajo supuestos en extremo conservadores, la participación de la violencia impulsiva en la capital no sobrepasa el 30\% del total de homicidios registrados anualmente. En contraste, bajo supuestos igualmente conservadores, a las expresiones instrumentales se les pude adjudicar dos terceras partes de los homicidios que ocurren en la ciudad.

\section{Concentración persistente de los homicidios en Bogotá}

Una conclusión que se desprende de los datos de homicidio en Bogotá, entre 1997 y 1999, es que el grueso de los incidentes no se distribuye de manera dispersa y aleatoria por toda la ciudad. Por el contrario, en la capital se observa un patrón de alta concentración de los homicidios; patrón que además es persistente en el tiempo. Esta evidencia por si sola, repre-

$20 \mathrm{Al}$ respecto la definición de una lesión por riña en una minuciosa encuesta sobre lesiones no fatales aplicada en Cali es reveladora: "cuando las personas involucradas se han enfrentado entre sí por causas no determinadas". Concha y Espinosa (1997). 
senta un desafío importante a la tesis comúnmente aceptada para Bogotá que explica la violencia homicida como un fenómeno difuso y accidental, producto de la intolerancia ciudadana.

\section{Concentración geográfica}

Entre 1997 y 1999, la concentración geográfica de las tasas de homicidio más altas de la ciudad se observa en tres focos compuestos por localidades contiguas en el centro, el sur-oriente y el sur-occidente de Bogotá.

Las zonas más violentas de la ciudad presentan un patrón según el cual:

- 20\% de los homicidios se concentran en 21 sectores censales donde reside el $5 \%$ de los habitantes;

- 50\% de los homicidios se concentran en 84 sectores censales donde reside el $25 \%$ de los habitantes;

- 80\% de los homicidios se concentran en 230 sectores censales donde reside el $60 \%$ de los habitantes.

Cuando se analiza la aglutinación de las muertes violentas en unos pocos lugares según los distintos tipos de violencia, impulsiva o instrumental, se obtienen resultados sorprendentes. En principio, cabría esperar que la primera, la violencia cotidiana y rutinaria, estuviera más dispersa entre los distintos sectores de la capital que la instrumental, la que resulta de los atracos o ajustes de cuentas, y que se puede pensar se limita a unos cuantos focos con altos índices de delincuencia o presencia de estructuras criminales. Sin embargo, los datos de homicidio de Bogotá indican que la violencia impulsiva tiende a tener un mayor grado de concentración que la instrumental $^{21}$.

21 El grado de concentración se midió utilizando el coeficiente de Gini - indicador tradicionalmente utilizado para medir el grado de concentración de la distribución del ingreso. Para los homicidios impulsivos se calculó un coeficiente de Gini de 0.43 frente a uno de 0.36 para los instrumentales. 
Por otro lado, y de manera también sorprendente, el grado de concentración geográfica de los homicidios sobre los cuales se desconoce el móvil es equiparable a la de los casos impulsivos. No obstante, las características de la concentración difieren ya que tienden a explicarse por los niveles de violencia. Así, para la violencia impulsiva la aglutinación se explica sobre todo por unos bajos niveles de violencia en los sectores más pacíficos de la ciudad. En contraste, para los homicidios sin información sobre el móvil, la mayor centralización se da en el otro extremo de la escala de violencia. Al ordenar las localidades de acuerdo a su participación en cada tipo de violencia, se encuentra que en los casos impulsivos, tan sólo el 10\% de los homicidios ocurren en los lugares en donde habita el $40 \%$ de la población. Para la violencia de causa desconocida, por el contrario, cerca del $40 \%$ de los incidentes ocurren en los lugares más violentos, en dónde habita tan sólo el 10\% de la población.

Otra variante que debe destacarse acerca de la concentración por tipos de violencia es que la categoría de la violencia impulsiva en el hogar, o sea aquella representada mayoritariamente por el maltrato contra los niños y las mujeres, se encuentra bastante dispersa por toda la ciudad como era de esperar.

Persistencia de la violencia

Otro fenómeno observable es la ausencia de cambios que modifiquen sustancialmente el patrón de concentración de los homicidios en Bogotá de un año a otro. Así se encontró que un buen predictor de la violencia homicida en una localidad sería simplemente el nivel de la tasa de homicidios, observado en esa misma localidad durante el período inmediatamente anterior. En efecto, entre localidades, la correlación entre las tasas de homicidio 
de 1999 y las de 1998 es del 99\% y la cifra respectiva para los niveles del 98 y del 97 es del $97 \%$.

El fenómeno de persistencia está asociado con los niveles de violencia y varia según el tipo manifestación. De este modo, por un lado, se observa que la correlación entre el número de homicidios ocurridos en dos años consecutivos tiende a hacerse más estrecha al moverse hacia arriba en la escala de la violencia (Gráfica 5). Por otro lado, se tiene que la mayor contribución a la persistencia proviene de los homicidios sobre los cuales no se tiene información del móvil y que la violencia impulsiva es menos persistente que la instrumental (Gráfica 6).

Desde la perspectiva de los principales móviles que componen los distintos tipos de violencia se destacan dos observaciones. La primera es que en la violencia instrumental el fenómeno de persistencia en el tiempo es más marcado para los llamados ajustes de cuentas que para los atracos. La segunda es que la baja perseverancia de la violencia impulsiva es particularmente notoria para la categoría del maltrato en el hogar. En esta medida es posible deducir, considerando además lo expuesto acerca de la dispersión geográfica de los homicidios causados en situaciones de violencia doméstica, que para el caso de Bogotá la categoría que bien podría explicarse dentro de la idea general de una violencia difusa, caracterizada por ser espacial y temporalmente poco previsible, es precisamente la de la violencia impulsiva en el hogar. 

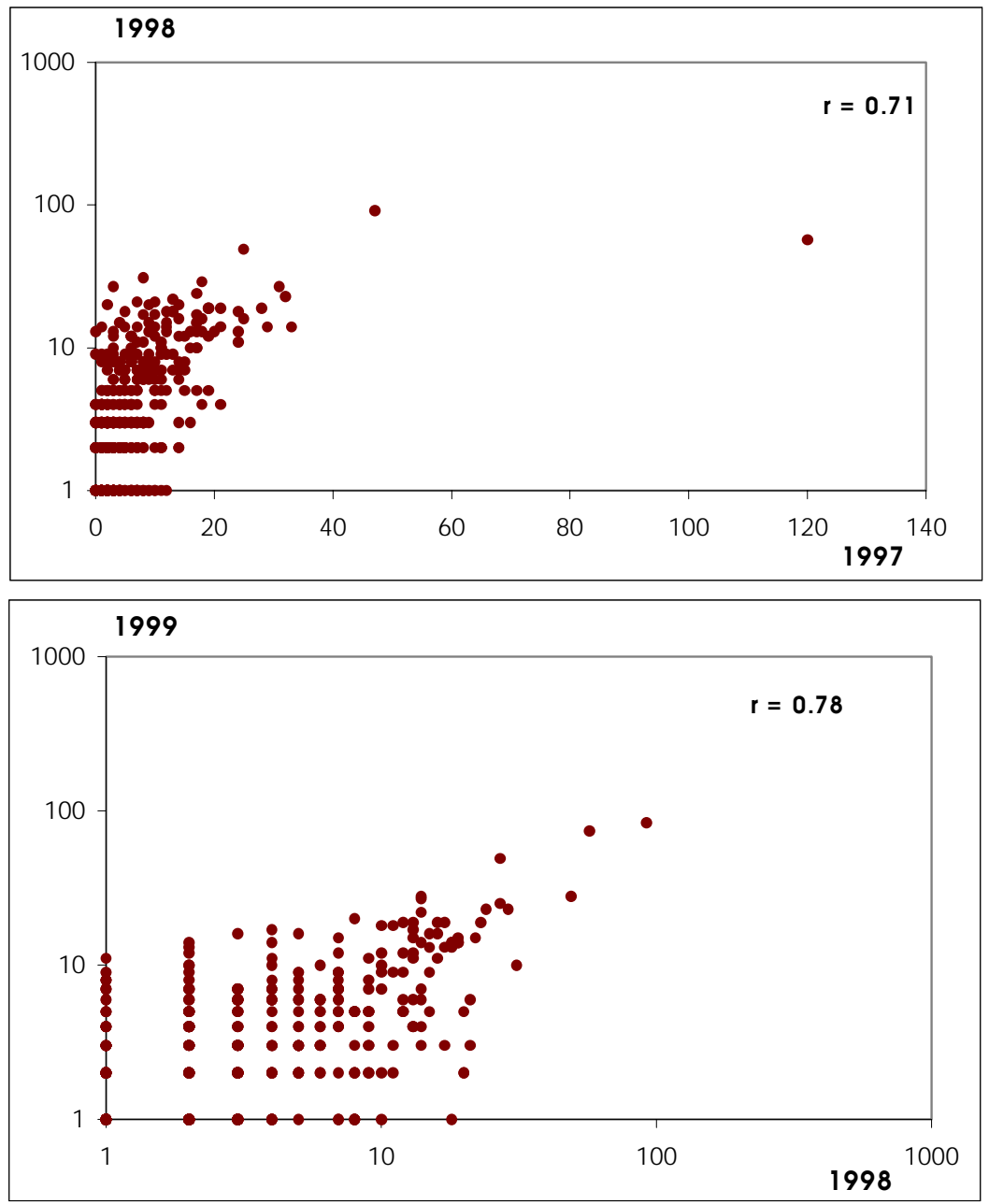

Fuente: Cálculos propios con datos Homicidios Medicina Legal - Sectores Infographics

Grafica 5. Persistencia de la violencia

Numero total de homicidos por sectores censales - Años consecutivos Escala Semi-Log 
VIOLENCIA IMPULSIVA
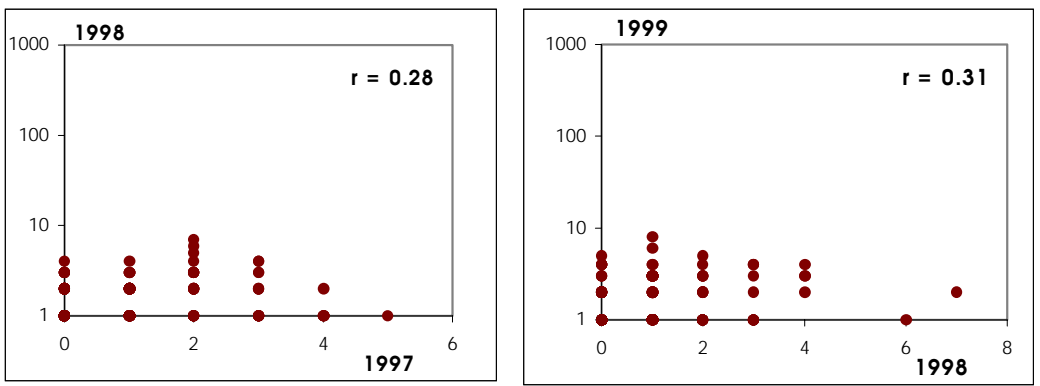

VIOLENCIA INSTRUMENTAL
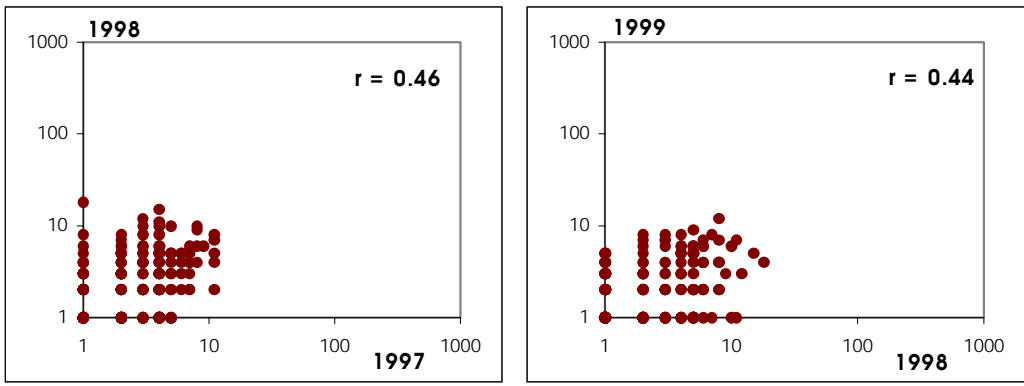

VIOLENCIA SIN INFORMACION SOBRE MOVILES
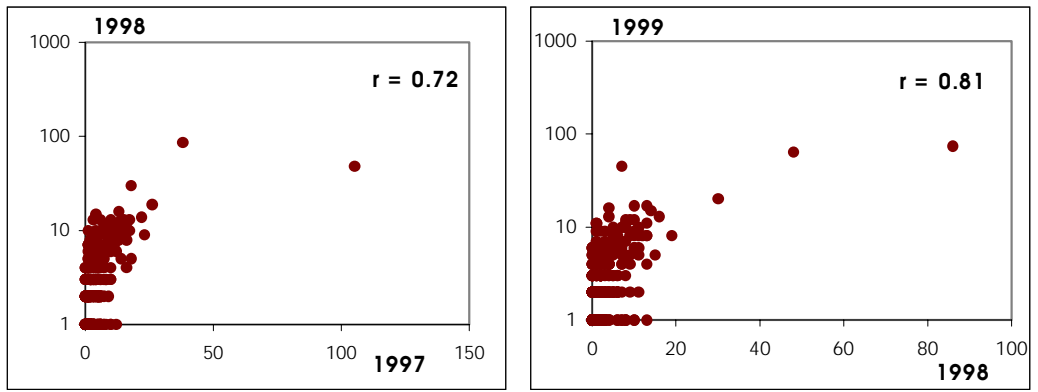

Fuente: Cálculos propios con datos Homicidios Medicina Legal - Sectores Infographics

Grafica 6. Persistencia de un año a otro por tipo de violencia

Número total de homicidios por sectores censales - Años consecutivos 


\section{Causas objetivas" de la violencia ${ }^{22}$}

La aproximación a la posible asociación entre violencia y factores sociales, tomando en cuenta los indicadores socioeconómicos disponibles de manera desagregada - por localidades y por sectores censales - para Bogotá, no dan sustento suficiente a la arraigada noción según la cual existen unas "causas objetivas" que explican la violencia urbana en el país.

Un primer factor evaluado es el demográfico. Se destaca ante todo la baja relación que se da entre número absoluto de muertes violentas, número de habitantes y crecimiento de la población: las localidades y sectores más violentos de Bogotá son precisamente aquellos menos poblados y en donde la población ha permanecido más estable. Más aún, los sectores donde se registra un mayor crecimiento demográfico muestran un número de homicidios inferior al promedio de la ciudad. Estas observaciones van en contra vía de la idea, vinculada al mito de las "causas objetivas", según la cual los flujos de población migrante, y más recientemente de desplazados, son una fuente primaria de los problemas de violencia en la ciudad.

Otro indicador demográfico disponible al nivel de localidad, la densidad poblacional o el hacinamiento, tampoco muestra una asociación estrecha con los índices de violencia. El único indicador demográfico que, aunque de forma leve, muestra cierta asociación con la tasa de homicidios es el índice de masculinidad o sea el porcentaje de hombres en el total de la población en una localidad. En aquellas localidades en las cuales la proporción de hombres dentro de la población es más baja se presentan tasas de homicidio inferiores al promedio. En el otro extremo, las localidades más violentas se caracterizan por contar con mayor participación masculina.

Un segundo factor evaluado es el de la pobreza, medido por el índice de necesidades básicas insatisfechas (NBI). El análisis de la relación entre la violencia homicida y este indicador no muestra, al nivel de las loca-

22 Para un análisis pormenorizado de este punto ver Rubio (2000). 
lidades capitalinas, ningún patrón definido. Ni las localidades más violentas se destacan por sus altos, o bajos, niveles de pobreza, ni las localidades más pobres - o las menos pobres - muestran ser peculiares en materia de violencia. Al nivel más desagregado de sector censal, este indicador muestra en cambio una relación negativa. En efecto, el grueso de los sectores con un número de homicidios superior al promedio se caracterizan por un bajo porcentaje de población con necesidades básicas insatisfechas, mientras que aquellos sectores en los que la población es mayoritariamente pobre presentan niveles de violencia que no superan el promedio de la ciudad. Más aún, cuando se utiliza el índice de miseria para medir la pobreza, esta relación negativa al nivel de sector censal, parece ser más clara.

Un tercer factor social analizado es el de la educación, en particular las deficiencias en el sistema educativo, medidas por dos indicadores disponibles al nivel de localidad, como son el analfabetismo y el índice de deserción escolar. Se observa una asociación positiva y una correlación cercana al $70 \%$ entre las tasas de homicidio y estos dos indicadores. Acerca de esta relación pueden hacerse dos comentarios. El primero es que, para Bogotá, la intensidad de tal asociación depende en buena medida de lo que ocurre en la localidad de Santa Fe, en donde confluyen alto analfabetismo, alta deserción escolar y altos índices de violencia. Si se excluye de la muestra esta localidad, la relación entre deficiencias en educación y tasa de homicidios se reduce sustancialmente (al 20\%). El segundo punto es que para el indicador de deserción escolar, se puede considerar la posibilidad de una causalidad en ambas vías.

Por otro lado, se debe anotar que otros elementos del sistema educativo, y en particular aquellos sobre los cuales se puede tener mayor incidencia a través de las políticas públicas, no muestran la relación esperada con los niveles de violencia. En efecto, ni el número de establecimientos de enseñanza pública, ni la relación entre docentes y alumnos en la secundaria parecen tener algún tipo de efecto sobre los índices de violencia. 
Para el primero de estos indicadores se percibe, por el contrario, una leve relación positiva que podría simplemente estar captando el efecto de una mayor proporción de jóvenes dentro de la población.

\section{Estructuras criminales y concentración de los homicidios en Bogotá}

El patrón descrito, según el cual la intensidad de la violencia tiende a concentrarse y a ser persistente en sectores que por lo general se encuentran agrupados y mantienen una continuidad geográfica, configurando focos críticos dentro y entre límites de diversas localidades, sugiere que más que producirse por causas accidentales, la violencia en Bogotá resulta de la acción sistemática y deliberada de actores que la promueven.

Un primer punto a favor de este argumento lo representa el efecto positivo percibido sobre los niveles de violencia en la ciudad de la presencia de estructuras criminales, así como de la actividad de tráfico de armas ${ }^{23}$. Otro punto, que serviría de apoyo a esta idea, es el hecho que una significativa porción de las víctimas de homicidio en la ciudad (cerca del 30\%) presentan algún tipo de antecedente de haber estado involucradas en actividades delictivas ${ }^{24}$.

Pero quizás la evidencia que más ayuda a ilustrar este punto es la cartográfica ${ }^{25}$. Desde esta perspectiva se encontró que los focos de violencia intensa en Bogotá tienden a coincidir con los escenarios donde la presencia de

\footnotetext{
23 Para realizar esta observación se construyó un indicador basado en el establecimiento de una calificación sobre presencia barrial de estas estructuras y de esta actividad, a partir de la base de datos producto del trabajo de campo. Posteriormente se calculó un promedio simple de esta calificación para el indicador al nivel del sector censal.

24 Este porcentaje, calculado a partir de la revisión de una muestra de protocolos de necropsia en Bogotá de los años 1997 y 1998 (Llorente, 2000), contrasta con la cifra encontrada en un estudio de Wellford y Cronin (1999) sobre homicidios en cuatro ciudades de los Estados Unidos, según el cual el 48\% de las víctimas tenían algún tipo de antecedente criminal. Esta diferencia puede explicarse por las marcadas desigualdades en cuanto al esclarecimiento de los hechos delictivos. Mientras que en las cuatro ciudades norteamericanas del estudio mencionado las autoridades resuelven en promedio el $74 \%$ de los casos, para Bogotá esa proporción no superaría en el mejor de los casos el 20\% de los homicidios. Esta anotación sugiere que la proporción de víctimas con antecedentes en Bogotá sin duda sería bastante superior a la enunciada.

25 El trabajo cartográfico se realizó a partir de la base de datos por barrios, producto del trabajo de campo. Esta información se agrupó en sectores censales, lo que permitió obtener un promedio para cada sector de los datos sobre estructuras criminales, actividades ilegales y lugares conflictivos - Promedio Sector Censal =(? indicador de presencia o intensidad / número de barrios afectados). Mediante una comparación con el promedio de Bogotá se identificaron los sectores donde las estructuras criminales tienen mayor incidencia, las actividades ilícitas son más recurrentes y los lugares conflictivos tienden a proliferar. Ver Echandía (2000).
} 
estructuras criminales es ostensible. Un ejercicio cartográfico detallado por sectores censales para el período 1997-99, arroja evidencia significativa en este sentido, en especial para aquellos que se distinguen por niveles intensos de violencia y alto grado de concentración de los homicidios (Echandía, 2000).

Se halló también una importante convergencia geográfica entre altos índices de violencia, presencia de estructuras criminales y abundancia de sitios donde se consume licor, que fueron identificados por la policía como particularmente conflictivos por las constantes riñas, escándalos y lesiones fatales y no fatales que escenifican ${ }^{26}$. Esta observación es consistente con la alta correlación encontrada, al nivel de localidades y sectores censales, entre las muertes por riñas y la violencia instrumental. Una conjetura que se podría hacer para explicar esta relación, es que estos lugares son conflictivos y escenarios de muertes violentas, no tanto en virtud de las riñas inducidas por el excesivo consumo de alcohol, sino más bien por causa del tipo de individuos que los frecuentan ${ }^{27}$.

Esta evidencia, a la luz de la geografía de la violencia homicida en Bogotá, resulta consistente con la tesis manejada por recientes estudios entre los que se destaca el de Cohen y Tita (1999), que llaman la atención sobre el hecho que los homicidios relacionados con estructuras organizadas, a diferencia de aquellos impulsivos, producto por ejemplo de la violencia doméstica, tienden a presentar un patrón espacial y temporal de difusión y contagio. Al respecto acuñan el sugerente término de difusión contagiosa según el cual la presencia de organizaciones que recurren a la violencia genera una dinámica que, por un lado, afecta a miembros de organizaciones rivales y por el otro, potencia una espiral de acciones violentas que se extienden espacialmente hacia sectores contiguos y que posteriormente tienden a persistir en el tiempo.

26 Entre estos sitios se encuentran bares, tabernas, prostíbulos, moteles, lugares de apuestas, billares.

27 Una anotación que serviría de apoyo a esta conjetura es la hecha por Klevens (1998, p. 15) a partir de una revisión extensa de estudios internacionales, según la cual "es posible que el alcohol simplemente se asocie con situaciones, ambientes o actividades específicas que incrementan el riesgo de exposición sin ser necesariamente un factor causal. Parece que el alcohol precipita reacciones violentas, pero sólo en personas con antecedentes de comportamiento agresivo o violento". 
Una variante de este fenómeno que parece ser especialmente pertinente para el caso de Bogotá es la definida como expansión de la difusión. Según ésta, la violencia se extiende de un foco inicial hacia sus alrededores, pero en el foco inicial se sigue presentando una alta incidencia del homicidio, en virtud del arraigo territorial característico de ciertos mercados ilegales y organizaciones criminales (Cohen y Tita, 1999, p. 454). La evidencia presentada respecto del grado de concentración de las muertes violentas en Bogotá y de la persistencia de este patrón, así como de la convergencia entre zonas altamente violentas y presencia de estructuras criminales, estaría sugiriendo este tipo de difusión.

\section{Conclusiones}

En Bogotá, así como en el conjunto de Colombia, el diagnóstico que se desprende de los mitos sobre la violencia urbana, ha sido la gran fuente de inspiración de las políticas públicas de la última década ${ }^{28}$. Dentro de este contexto, se le ha dado prioridad a políticas preventivas dirigidas al grueso de la población, en detrimento de medidas de control concentradas en unos pocos actores violentos.

Así, a partir de supuestos explicativos de la violencia impulsiva como la intolerancia y la cultura, se le otorga un papel preponderante a la educación, entendida en un sentido amplio que incluye la posibilidad de alterar la cultura, las creencias y las actitudes hacia la violencia. Adicionalmente, se favorece el gasto público para tratar de alterar las condiciones sociales y económicas que supuestamente ayudan a explicar la persistencia de varias formas de violencia. Desde el punto de vista del control, se favorecen ciertas medidas como las restricciones al porte de armas de fuego o al consumo de alcohol, pero éstas también dirigidas al grueso de la población y enmarcadas dentro de discursos preventivos orientados hacia 
cambiar las actitudes de los ciudadanos del común frente al porte de armas y al consumo de alcohol ${ }^{29}$.

Las políticas en materia de violencia urbana en el país se han sustentado en un diagnóstico que no ha sido suficientemente contrastado con los datos. Además, sus efectos han sido evaluados de manera poco rigurosa, llegándose a conclusiones burdas como que los descensos observados en las tasas de homicidio en algunas ciudades, entre ellas Bogotá, son resultado directo de las medidas de control al consumo de alcohol y al porte de armas de fuego ${ }^{30}$.

Del diagnóstico presentado para el caso de Bogotá, se desprenden varias conclusiones que tienen importantes implicaciones en materia de política pública:

En Bogotá la violencia instrumental es más preponderante que la impulsiva. La violencia cotidiana, rutinaria y baladí de la capital, fruto de la intolerancia, en ningún caso sobrepasa la barrera de los diez homicidios por cien mil habitantes. Lo que predomina en Bogotá es la dimensión instrumental, los homicidios producto de atracos y ajustes de cuentas, la cual exhibiría una tasa del orden de los treinta homicidios por cien mil habitantes que, por sí sola y como promedio agregado para la capital, ya es preocupante. Las medidas de prevención de la violencia homicida no deberían seguir orientadas exclusivamente a aquellas manifestaciones que aparecen como las menos protuberantes.

Los homicidios en Bogotá están concentrados en unos pocos focos críticos. Las muertes violentas en Bogotá están altamente concentradas en unos pocos focos críticos, los cuales son persistentes en el tiempo. Estos focos, además, se pueden asimilar a un escenario de difusión contagiosa de los homicidios, al

\footnotetext{
29 En Bogotá desde 1995 se han adoptado medidas de esta índole como la llamada Ley Zanahoria, que restringe el horario para la venta y consumo de alcohol, y como el denominado Plan Desarme, con el cual se restringe el porte de armas de fuego los fines de semana y festivos y se hacen campañas invitando a la población a entregar sus armas.

30 Evaluaciones preliminares sobre las medidas de restricción al consumo de alcohol y al porte de armas de fuego en Bogotá, indican que estos controles han tenido un impacto bastante moderado sobre la tendencia de homicidios de la ciudad, contrariamente a lo que ha sostenido públicamente la Administración Distrital (Llorente et alii, 2000).
} 
converger en ellos alta intensidad y concentración de la violencia con presencia de estructuras criminales. Frente a esta situación, el diagnóstico de la violencia predominantemente impulsiva y difusa pierde aún más sentido. Como también lo pierde la justificación y la pertinencia de las medidas supuestamente preventivas dirigidas a toda la población, a tratar de cambiar sus actitudes, o su cultura, o sus hábitos de esparcimiento. Claramente, al nivel de los agresores, el grueso de la violencia en la capital no es un problema de todos los bogotanos, ni siquiera de muchos de ellos. Las medidas orientadas a disminuir la violencia no pueden seguir pasando por alto esta realidad.

¿Cultura de la violencia? La dinámica de la violencia en Bogotá desde los noventa según la cual en el término de diez años se duplicaron las tasas de homicidio para luego reducirse a la mitad, y el hecho que las altas tasas se circunscriban a unas pocas zonas, parece poco compatible con la idea de una violencia determinada culturalmente. Cualquier definición de cultura ${ }^{31}$, lleva implícita no solamente la noción de largo plazo sino de cambios que, cuando se dan, son lentos y graduales. No parece razonable sugerir que una misma generación pueda sufrir más de un cambio culturalde importancia a lo largo de su vida, ni mucho menos dos transformaciones de sentido opuesto. Cabría preguntarse entonces ¿Cuál puede ser la definición de cultura de la violencia compatible con tal heterogeneidad espacial o con un aumento y una reducción importantes en una sola década? ¿Se consolidó rápidamente, y en unos cuantos barrios de la ciudad, una cultura violenta para luego, también de manera acelerada, desvanecerse? Vale la pena recordar que lo que ha sido reconocido como un cambio importante en las actitudes hacia la violencia, la pacificación de las costumbres en Europa occidental descrita por Norbert Elías, fue un proceso de varios siglos y en una sola dirección, no de una década y en dos sentidos diferentes. Además, no se trató nunca de un proceso circunscrito a unos pocos lugares.

31 Incluso la definición adoptada por analistas de la violencia en Colombia: "El conjunto de normas, actitudes, valores y creencias transmitidos, aprendidos y compartidos por un grupo social que le da coherencia a la manera como sus miembros, o un subgrupo de ellos, actúan, interpretan y responden a las circunstancias" (Duque y Klevens, 2000, p. 190). 
Los pocos lugares muy violentos de la ciudad lo son en todos los sentidos. Geográficamente, las dos grandes categorías de la violencia - la impulsiva y la instrumental - están no sólo asociadas entre sí, sino además, altamente correlacionadas con aquellos homicidios donde la información es insuficiente para establecer un posible móvil. Esto indica que los pocos lugares muy violentos en la ciudad lo son en todos los sentidos. La evidencia sobre esta asociación es insuficiente para apoyar la tesis que, como una extensión de la teoría de la intolerancia, plantea que de las expresiones impulsivas menos graves - violencia doméstica- se va escalando hacia manifestaciones como las riñas en los bares con resultados fatales y después al crimen organizado. Esta asociación simplemente lo que estaría indicando es que en los pocos focos con alta incidencia de violencia organizada, también es alto el nivel de riñas que resultan fatales, así como de homicidios de causa desconocida. En términos de política pública esto implicaría que el control de las estructuras criminales existentes en la ciudad sería, además, una buena manera de prevenir homicidios impulsivos, en especial aquellos originados en riñas.

La tesis sobre las "causas objetivas" de la violencia no recibe un respaldo significativo de los datos disponibles para Bogotá. La asociación entre las tasas de homicidio y cualquiera de los indicadores analizados de las condiciones sociales es, en el mejor de los casos, imperceptible. Las historias persistentes sobre los flujos de población migrante, y más recientemente de desplazados, como la fuente primaria de los problemas de violencia no se corroboran con la evidencia disponible. Para los indicadores de presencia del Estado, la asociación es incluso contraria a la esperada: las zonas mejor atendidas por el sector público son, por lo general, más violentas que las abandonadas. A la luz de estos resultados, parecería poco pertinente seguir confundiendo las nociones de necesidades, o derechos, no satisfechos, incluso la protesta social, con la de violencia. Y en materia de política pública sería recomendable que tampoco se confundan las probablemente crecientes responsabilidades públicas en aliviar y satisfacer esas necesidades con la la- 
bor, más específica, de prevenir la violencia homicida.

En fin, lo que se observa es que el diagnóstico público sobre el homicidio en un centro urbano como Bogotá, no puede seguir ignorando la violencia que se genera a partir de las estructuras criminales que operan en la ciudad. En este sentido parece pertinente que en el diseño de las políticas preventivas, se tome como punto de partida el control de estas estructuras a efectos de recuperar un umbral mínimo de seguridad pública en sectores críticos de la ciudad, donde la violencia ha sido intensa de manera persistente. En una de las revisiones más ambiciosas recientemente efectuada sobre los programas de prevención del crimen en los Estados Unidos durante los últimos treinta años (Sherman et alii, 1998), se concluye que el grado de violencia de un determinado lugar o comunidad hacia donde se estén orientando iniciativas preventivas, es un aspecto crítico para la eficacia de las mismas en términos de reducción del crimen. En esta medida se sugiere precisamente la recuperación de un cierto nivel de seguridad, particularmente a través de actividades focalizadas de control, el cual, una vez logrado, permitiría incrementar la eficacia de las acciones en los otros campos sustantivos para la prevención del crimen - la familia, las comunidades, las escuelas y la fuerza laboral.

Resulta pertinente entonces, un cambio de enfoque que permita pasar de las políticas generales que buscan incidir sobre el conjunto de los ciudadanos, hacia políticas que aborden los fenómenos de violencia de manera focalizada geográficamente, con el objeto de identificar aquellos factores de riesgo peculiares a las zonas donde la violencia es intensa y persistente.

\section{Referencias}

ALCALDÍA MAYOR DE BOGOTÁ. Plan Desarme. Bogotá: Imprenta Distrital, 1996.

ALCALDÍA MAYOR DE BOGOTÁ. Políticas saludables para la seguridad y la convivencia. Bogotá: Imprenta Distrital, 1997. 
ALCALDÍA MAYOR DE BOGOTÁ. Seguridad y violencia en Santa Fe de Bogotá. Bogotá: Imprenta Distrital, 1997a.

ARRIAGADA, I. y GODOY, L. Seguridad ciudadana y violencia en América Latina: diagnóstico y políticas en los Años Noventa. Santiago de Chile: Naciones Unidas y CEPAL - Serie Políticas Sociales, 1999.

BUVINIC, M; MORRISON, A. y SHIFTE, M. La Violencia en América Latina y el Caribe. Un marco de referencia para la acción. Washington D.C.: BID - Serie de Informes Técnicos del Departamento de Desarrollo Sostenible, 1999.

BUVINIC, Mayra y MORRISON, Andrew. Notas técnicas. Prevención de la violencia. Washington D.C.: BID, 1999.

COHEN, J. y TITA, G. Diffusion in Homicide: Exploring a General Method for Detecting Spatial Diffusion Processes. In: Journal of Quantitative Criminology, vol. 15, no. 4, 1999.

Comisión de Estudios sobre la Violencia Colombia: Violencia y Democracia. Informe Presentado al Ministerio de Gobierno. Bogotá: Universidad Nacional de Colombia, 1987.

CONCHA y ESPINOSA. La violencia en Colombia: dimensiones y políticas de prevención y control. Lesiones personales no fatales. Cali: Cisalva - Universidad del Valle. Mimeo, 1997.

Departamento Nacional de Planeación. La Paz: el desafío para el desarrollo. Bogotá: Tercer Mundo Editores, Departamento Nacional de Planeación, 1998.

DUQUE, L. F. y KLEVENS, J. Creencias, Actitudes y Prácticas Asociadas con la Violencia en Bogotá. In: Coyuntura Social, no․ 22. Bogotá: Fedesarrollo e Instituto SER de Investigación, 2000.

DUQUE, L. F. y KLEVENS, J. Estudio de epidemiología de la violencia en Santa Fe de Bogotá. Informe Técnico presentado a Colciencias. Bogotá: Mimeo, 1997.

ECHANDÍA, C. Geografía de la violencia homicida en Bogotá. Investigación "Caracterización de la Violencia Homicida en Bogotá", Documento de Trabajo No. 2. Bogotá: Paz Pública-CEDE-UNIANDES y Alcaldía de Bogotá, 2000. 
Sociologias, Porto Alegre, ano 4, no 8, jul/dez 2002, p. 172-205

ECHANDÍA, C. El conflicto armado y las manifestaciones de violencia en las regiones de Colombia. Bogotá: Presidencia de la República, Observatorio de Violencia de la Oficina del Alto Comisionado para la Paz, 1999.

ECHANDÍA, C. Dimensión Regional del Homicidio en Colombia. In: Coyuntura Social, no. 17. Bogotá: Fedesarrollo e Instituto SER de Investigación, 1997.

ECHANDÍA, C. Dimensión económica de la violencia y de la criminalidad. In: Problémes d’Amerique Latine, no. 16, Paris, 1995.

ECHANDÍA, C. Violencia y Desarrollo en el Municipio Colombiano. In: Boletín Estadístico, no..476. Bogotá: DANE, 1992.

FAJNZYLBER, P.; LEDERMAN, D. y LOAYZA, N. Inequality and Violent Crime. Documento de Trabajo preparado dentro del Proyecto "Crimen y Violencia en América Latina", auspiciado por el Banco Mundial. Mimeo, 1999.

GAVIRIA, A. Increasing returns and the evolution of violent crime: the case of Colombia. Washington D.C.: BID. Mimeo, 1999.

JIMENO, M. y ROLDÁN, I. Las sombras arbitrarias. violencia y autoridad en Colombia. Bogotá: Editorial Universidad Nacional, 1996.

JONSON, E. y MONKKONEN, E. (Eds). The civilization of crime. violence in town \& country since the middle ages. Urbana: University of Illinois Press, 1996.

KLEVENS, J.; ROCA, J.; RESTREPO, O. y MARTINEZ, A. Risk Factors for Adult Male Criminality in Colombia. Bogotá: Universidad Javeriana. Mimeo, 1999.

KLEVENS, J. y ROCA, J. Nonviolent youth in a violent society: resilience and vulnerability in the country of Colombia. In: Violence and Victims, vol. 14, no‥ 3, 1999.

KLEVENS, J. Violencia y Delincuencia. Factores de Riesgo y Medidas de Prevención. In: Lesiones de causa externa. Factores de riesgo y medidas de prevención. Bogotá: Instituto Nacional de Medicina Legal y Ciencias Forenses, 1998.

LLORENTE, M. V. Circunstancias de los homicidios en Bogotá y perfil de las víctimas: una aproximación. Investigación "Caracterización de la Violencia Homicida en Bogotá", Documento de Trabajo no․ 5. Bogotá: Paz Pública-CEDEUNIANDES y Alcaldía de Bogotá, 2000. 
LLORENTE, M. V.; NÚÑEZ, J. y RUBIO, M. Efecto de los controles al consumo de alcohol y al porte de armas de fuego sobre los homicidios en Bogotá. Investigación "Caracterización de la Violencia Homicida en Bogotá", Documento de Trabajo no. 6. Bogotá: Paz Pública-CEDE-UNIANDES y Alcaldía de Bogotá, 2000.

LONDOÑO, J. L. y GUERRERO, R. Violencia en América Latina: epidemiología y costos. Washington: BID - Serie Documentos de Trabajo de la Red de Centros, no . 375, 1999.

NIÑO, S.; LUGO, N.; ROZO, C. y VEGA, L. Los Territorios del Miedo en Santa Fe de Bogotá. Bogotá: Tercer Mundo Editores, Observatorio de la Cultura Urbana e Instituto Colombiano de Antropología, 1998.

PAZ PÚBLICA. Escenarios del crimen en los barrios y localidades de Bogotá. Investigación "Caracterización de la Violencia Homicida en Bogotá", Documento de Trabajo No. 1. Bogotá: Paz Pública-CEDE-UNIANDES y Alcaldía de Bogotá, 2000 .

PAZ PÚBLICA. Caracterización de la violencia homicida en dos localidades de Bogotá. Investigación "Caracterización de la Violencia Homicida en Bogotá", Documento de Trabajo no. 3. Bogotá: Paz Pública-CEDE-UNIANDES y Alcaldía de Bogotá, 2000a.

PAZ PÚBLICA. Mitos del homicidio en Colombia, Carta no. 1. Bogotá: Paz Pública-CEDE-Universidad de Los Andes, 1997.

Presidencia de la República. Seguridad para la gente. Segunda Fase de la Estrategia Nacional contra la Violencia. Bogotá, octubre, 1993.

REISS. A. J. y ROTH, J.A. Violence: understanding and preventing. Washington, D.C.: National Academy Press, 1993.

RUBIO, M. Estudio interpretativo de la violencia homicida en Bogotá. Investigación "Caracterización de la Violencia Homicida en Bogotá", Documento de Trabajo no. 4. Bogotá: Paz Pública-CEDE-UNIANDES y Alcaldía de Bogotá, 2000.

RUBIO, M. y LLORENTE, M. V. Procesos sobre homicidios en Bogotá. Análisis estadístico de una muestra de expedientes en juzgados penales y unidades de fiscalía en Bogotá. Investigación "Caracterización de la Violencia Homicida en Bogotá", Documento de Trabajo no. 7. Bogotá: Paz Pública-CEDE-UNIANDES y Alcaldía de Bogotá, 2000. 
Sociologias, Porto Alegre, ano 4, no 8, jul/dez 2002, p. 172-205

RUBIO, M. y LLORENTE, M. V. Crimen e impunidad: precisiones sobre la violencia. Bogotá: Tercer Mundo Editores y CEDE, 1999.

RUBIO, M. y LLORENTE, M. V. La Justicia en una Sociedad Violenta. In: DEAS, M. y LLORENTE, M.V. (eds.) (1999) Reconocer la guerra para construir la paz. Bogotá: Norma, Cerec, Uninades, 1999a.

RUBIO, M. y LLORENTE, M. V. Casos Juzgados. Análisis de una encuesta de sentencias penales en cuatro ciudades colombianas (1995-1996). Informe Final de Investigación, Consejo Superior de la Judicatura, Bogotá, 1998.

RUBIO, M. y LLORENTE, M. V. De las Riñas a la Guerra. Hacia una Reformulación del Diagnóstico de la Violencia en Colombia. In: Coyuntura Social, no․ 17. Bogotá: Fedesarrollo e Instituto SER de Investigación, 1997.

SÁNCHEZ, F. y NÚÑEZ, J. Determinantes del crimen violento en un país altamente violento: el caso de Colombia. Bogotá: CEDE-Universidad de Los Andes. Mimeo, 2000.

SARMIENTO, A. Violencia y Equidad. In: Planeación y Desarrollo, vol. XXX, no․ 3. Bogotá: Departamento Nacional de Planeación, 1999.

SHERMAN, L.; GOTTFREDSON, D.; Mackenzie, D.; ECK, J.; REUTER, P. y BUSHWAY, S. Preventig crime: what works, what doesn't, what's promising. A report to the United States Congress, http://www.njrs.org/works/index.htm.1998.

SPIERENBURG, Pieter. Long-term trends in homicide: theoretical reflections and dutch evidence, fifteenth to twentieth centuries. In: Johnson y Monkkonen, 1996.

WELLFORD, C. y CRONIN, J. An analysis of variables affecting the clearance of homicides: a multistate study. Justice Research and Statistics Association. http:// www.jrsa.org/, 1999. 


\section{Resumen}

Desde mediados de la década de los noventa la tasa de homicidios en Bogotá ha descendido continuamente y ha llegado a niveles relativamente bajos dentro del contexto urbano nacional. Aún así, la intensidad de la violencia en el distrito sigue siendo considerable bajo cualquier parámetro internacional y en algunos sectores de la ciudad se registran tasas de homicidio verdaderamente altas. En este artículo se hace una aproximación a la incidencia de estructuras criminales en los niveles de homicidio de la ciudad, a partir de un análisis de las distintas manifestaciones de la violencia y del patrón espacial y de difusión de los homicidios en Bogotá.

Tres conclusiones centrales se desprenden de la evidencia sobre violencia homicida en Bogotá para el período 1997-1999: 1) las muertes violentas están altamente concentradas en unos pocos focos y este patrón geográfico es persistente en el tiempo, 2) la violencia de tipo instrumental (los homicidios producto de ajustes de cuentas y de atracos) aporta un mayor número de muertes que la impulsiva (los homicidios resultado de agresiones en el hogar y de riñas callejeras que al calor de los tragos culminan fatalmente), y 3) existe una importante convergencia geográfica entre focos de intensa violencia y presencia de estructuras criminales asociadas a mercados ilegales y a actividades ilícitas y del "bajo mundo". Estas conclusiones controvierten el diagnóstico preponderante en Colombia que le da un mayor peso a los fenómenos urbanos de violencia producto de problemas generalizados de convivencia ciudadana, en particular la intolerancia, y que minimizan o ignoran aquellos que resultan del progresivo aumento de la delincuencia organizada.

Palabras-clave: violencia urbana, homicidios, mapeo del crimen, políticas seguridad, ciudadana, Colombia. 